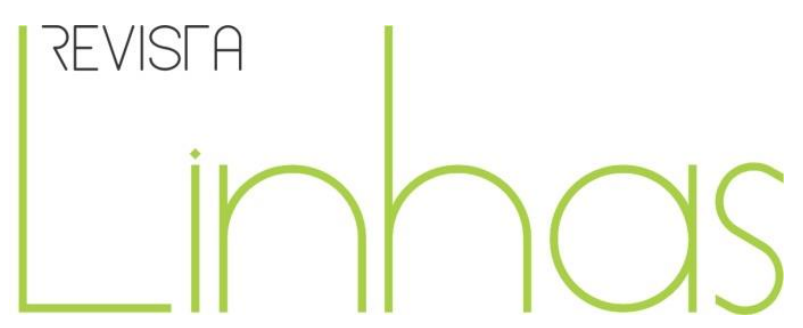

\title{
A Agenda Global da Educação no contexto da Covid-19
}

\section{Resumo}

A partir da globalização neoliberal, acentuou-se uma semelhança entre as reformas empreendidas no campo educacional no mundo, constituindo-se uma Agenda Global da Educação. Tendo em vista formar o chamado capital humano, alguns organismos internacionais como o Banco Mundial, a OCDE e a Unesco vêm exercendo o papel de elaboradores dessas "políticas viajantes" que constituem a Agenda Global; as Redes Políticas têm sido os vetores da disseminação das ideias e estratégias que devem conformar as políticas públicas. $O$ artigo tem como objetivo apresentar as diferentes abordagens do que vem se chamando de Agenda Global da Educação, manifestada por meio de políticas ou reformas ou movimentos educacionais globais, analisando o papel desempenhado pelos organismos internacionais nesse processo e identificando as principais recomendações feitas aos países. No momento da pandemia provocada pela Covid-19, organismos internacionais tomaram a frente das ações concernentes à educação, elaborando recomendações, traçando estratégias e coordenando ações relacionadas à educação, ao funcionamento das escolas, à utilização de plataformas digitais e à avaliação do processo. Um dos pontos de destaque no texto é o foco dessas entidades, nesse período pandêmico, na formação do capital humano na lógica mercantilista. O artigo é resultante de uma pesquisa documental sobre a Internacionalização das Políticas Educacionais, financiada pelo CNPq, tendo como sustentação teórico-metodológica o materialismo histórico e dialético.

Palavras-chave: Agenda Global da Educação; Organismos internacionais; Covid-19.

\section{Olgaíses Cabral Maues}

Universidade Federal do Pará UFPA - Belém/PA - Brasil olgaises@uol.com.br

\section{Para citar este artigo:}

MAUES, Olgaíses Cabral. A Agenda Global da Educação no contexto da Covid-19. Revista Linhas. Florianópolis, v. 22, n. 49, p. 187-216, maio/ago. 2021. 


\title{
The Global Education Agenda in the Context of Covid-19
}

\begin{abstract}
From neoliberal globalization, a similarity of the reforms undertaken in the educational field was accentuated, constituting a Global Education Agenda. In order to form the so-called human capital, some international organizations such as the World Bank, the OECD and UNESCO have been playing the role of the elaborators of these "traveling policies" that constitute the Global Agenda and the Political Networks have been the vectors of the dissemination of ideas and strategies that should conform public policies. The paper aims to present the different approaches from what has been called the Global Education Agenda, which has been manifested through policies or reforms or global educational movements, analyzing the role played by international organizations in this process and identifying the main recommendations made to countries. At the time of the pandemic caused by Covid-19, international organizations took the lead in actions related to education, developing recommendations, designing strategies and coordinating actions related to education, the functioning of schools, the use of digital platforms and the evaluation of the process. One of the highlights in the text is the focus of these entities in this pandemic period, with the formation of human capital, in the mercantilist logic. The aim is the result of a documentary research on the Internationalization of Educational Policies, funded by CNPq, having the historical and dialectical materialism as theoretical and methodological support.
\end{abstract}

Keywords: Global Education Agenda; International organizations; Covid-19. 
A pandemia que se abateu sobre o planeta a partir do final de 2019 modificou todas as atividades econômicas, políticas e sociais em função da letalidade do vírus SarsCoV-2 que, até o final do primeiro trimestre do ano de 2021, tinha matado 2,9 milhões de vidas e infectado 70,62 milhões de pessoas no mundo. As consequências dessa catástrofe sanitária ainda estão sendo dimensionadas nas diferentes esferas das sociedades, mas há estudos indicando, além das mortes, as perdas financeiras oriundas do fechamento da economia, em função da exigência do confinamento, imposto em alguns países como medida para diminuir a transmissão do vírus. Segundo o Fundo Monetário Internacional (FMI, 2021), a economia mundial teve uma contração de cerca de 3,5\% em 2020, o que, por certo, terá um impacto significativo nos anos seguintes, atingindo a cadeia produtiva, com graves consequências para as políticas sociais, incluindo a educação.

Sabe-se que antes do evento do Sars-CoV-2, o mundo estava interligado pelo processo de globalização que tem como objetivo central a expansão dos mercados em nível planetário, a realização da acumulação flexível, alargando o sentido de forças produtivas, mudando o papel do Estado na relação com o mercado e nos compromissos com os direitos sociais. Esse processo acabou criando uma Agenda Global da Educação que vem sendo implementada sob a coordenação de alguns organismos internacionais (OI), pelos chamados think tanks, empresários, organizações sociais e representantes da sociedade civil. No momento da pandemia provocada pela Covid-19, alguns desses protagonistas tomaram a frente nas ações concernentes à educação, elaborando recomendações, traçando estratégias e coordenando ações relacionadas à propagação do vírus e aos efeitos para a educação.

O fato de haver uma rede internacional de educação fez com que as concertações, estabelecidas com os governos de diferentes países, se voltassem para tratar do problema comum que perpassava a todos, movimentando organismos internacionais na busca de estratégias para garantir o funcionamento do processo educacional durante a crise sanitária e após sua superação, levando-se em conta as disparidades nacionais, regionais e internacionais. 
O objetivo do artigo, resultante de uma pesquisa documental, com base no materialismo histórico e dialético, é analisar a Agenda Global da Educação, seus fundamentos e a relação desta, por meio de Ols, com a elaboração de estratégias e ações no campo da educação a serem executadas durante e pós pandemia da Covid-19. O texto está constituído de três momentos, a saber: primeiramente, serão analisados alguns movimentos globais da educação que aconteciam e que foram intensificados com o processo da globalização. Essa abordagem tem como objetivo evidenciar a forma como a educação vem sendo pensada e conduzida no mundo, analisando algumas fontes consideradas seminais para o surgimento desse movimento global, as quais incluem a globalização econômica e o neoliberalismo que pavimentam o terreno para a implantação de políticas educacionais em âmbito mundial e têm como distintivo a lógica empresarial. Na sequência, se abordará o papel dos Ols, protagonistas das políticas mundiais da educação, intensificado na pandemia provocada pelo Sars-CoV-2, procurando demonstrar que as ações propostas estão inseridas na lógica da Agenda Global da Educação, analisando-se algumas diretrizes e recomendações apresentadas. Nas conclusões, serão evidenciadas as relações entre esses dois momentos que são, na realidade, partes de um só processo.

\section{As políticas educacionais mundiais}

A globalização econômica, face da internacionalização do capital, tem utilizado o neoliberalismo para possibilitar a implantação dos mecanismos necessários para o desenvolvimento de políticas que assegurem a expansividade da acumulação capitalista, agora em termos planetários. O desenvolvimento real do processo de globalização teve o suporte de uma teoria política, o neoliberalismo, que defende uma concepção de Estado mais flexível, cujo objetivo central é permitir o avanço dos interesses privados. Para tanto, houve necessidade de uma base de sustentação, sendo a Nova Gestão Pública (NGP), paradigma para a administração, a ferramenta forjada para permitir o fechamento do ciclo de apoio a mais uma etapa do capitalismo que, na atualidade, é denominada de financeirização. É com essa moldura, envolvendo a globalização, o neoliberalismo e a Nova Gestão Pública, que será analisada a constituição de uma Agenda Global da Educação, materializada de forma mais evidente a partir dos anos de 1990. 
O arcabouço político, jurídico e econômico, criado pela Globalização e pelo neoliberalismo, cujo centro é a necessidade de o capital intensificar a exploração dos mercados existentes e a possibilidade de abrir novos, dá sustentação, de forma mais profunda, à premência de se formar o trabalhador que possa responder a esses anseios do processo de acumulação.

Nesse contexto, a educação desempenha um papel fundamental, devendo-se, para tanto, criar as condições objetivas, possibilitando a elaboração e a operacionalização de políticas que correspondam à demanda do capital. Desde os anos 1990, esse movimento se torna mais intenso, indicando que antes, logo no pós-guerra, existiam ações nessa direção, quais sejam, de colocar a educação a serviço do capital. Afinal, é naquele momento, metade dos anos 40 do século $\mathrm{XX}$, que surgem os principais organismos internacionais que, ao longo do tempo, passaram a desempenhar um papel fundamental em relação às políticas educacionais. Dentre essas organizações, sobrelevam, pelas ações desenvolvidas em relação à educação, o Banco Mundial (BM)1, a Organização para a Cooperação e o Desenvolvimento Econômico $(O C D E)^{2}$ e a Organização das Nações Unidas para a Educação, a Ciência e a Cultura (UNESCO) ${ }^{3}$.

A Conferência Mundial de Educação, realizada em Jomtien, em 1990, e o Fórum Mundial de Educação, ocorrido em 2000, em Dakar, e em 2015, em Incheon, foram eventos promovidos e apoiados por Ols que aprovaram declarações assinadas pelos países participantes, as quais traduzem as preocupações dos signatários e das entidades internacionais organizadoras e apoiadoras em relação à "educação para todos" (UNESCO, 1990; 2000) e "educação inclusiva e equitativa de qualidade, ao longo da vida para todos" (UNESCO, 2015). A Declaração de Incheon incluiu o Marco de Ação 2030 que visa implementar o Objetivo de Desenvolvimento Sustentável 4 (ODS) ${ }^{4}$ que é o de

\footnotetext{
${ }^{1}$ Fundado em 1944 como Banco Internacional de Reconstrução e Desenvolvimento, BIRD.

${ }^{2}$ Criada em 1948 como Organização para a Cooperação Econômica Europeia, OCEE.

3 Criada em 1946 como agência especializada da Organização das Nações Unidas, ONU.

4 Os Objetivos de Desenvolvimento Sustentável são um apelo global à ação para acabar com a pobreza, proteger o meio ambiente e o clima e garantir que as pessoas, em todos os lugares, possam desfrutar de paz e de prosperidade. Estes são os objetivos para os quais as Nações Unidas estão contribuindo a fim de que possamos atingir a Agenda 2030 no Brasil. São 17 os ODS, sendo o de número 4 referente à Educação. Referidos objetivos devem ser atingidos até 2030.
} 
“assegurar a educação inclusiva e equitativa de qualidade, e promover oportunidades de aprendizagem ao longo da vida para todos" (UNESCO, 2015, p.1).

Algumas ações foram desenvolvidas por Ols, com repercussões no Brasil, visando o cumprimento das Declarações resultantes das Conferências e Fóruns. O BM elaborou um documento intitulado Prioridades e estratégias para a educação (1996), no qual são traçadas as principais recomendações para os países em relação à educação básica. Também foi elaborado um documento orientador denominado Ensino Superior, lições derivadas da experiência" (BANCO MUNDIAL, 1995). A UNESCO (1998) constituiu uma Comissão Internacional sobre Educação para o Século XXI, que elaborou o relatório intitulado Educação: um tesouro a descobrir, no qual são indicados quatro pilares que devem sustentar a educação: aprender a conviver, aprender a conhecer, aprender a fazer e aprender a ser. O capítulo I do documento anuncia o processo que deve ocorrer, partindo da comunidade local até a sociedade mundial.

Por sua vez, a OCDE, em 2000, começou a desenvolver o Programme for International Student Assessment 5 (PISA). Uma avaliação internacional comparativa, em 2004, realizou uma pesquisa entre os países membros para discutir como atrair, formar e reter professores eficazes. Em 2008, iniciou-se uma pesquisa visando conhecer as condições de trabalho de professores, a Teaching and Learning International Survey ${ }^{6}$ (TALIS). Ou seja, existe uma série de ações sendo desenvolvidas, abrangendo o mundo, no sentido de criar uma linha comum de ação no que diz respeito à educação.

\section{Agenda Global}

A crise do capital e a necessidade da recomposição da classe trabalhadora, nos moldes demandados pela acumulação flexível, têm impulsionado cada vez mais o processo de internacionalização da educação, no escopo de formar uma mão de obra qualificada com base nas demandas do mercado mundial. Com o arcabouço econômico, político, jurídico e administrativo, respaldado pela globalização, pelo neoliberalismo e

\footnotetext{
${ }^{5}$ Programa Internacional de Avaliação de Estudantes é um estudo comparativo realizado pela OCDE, a cada três anos, e oferece informações sobre o desempenho dos estudantes na faixa dos 15 anos.

${ }^{6}$ Pesquisa Internacional sobre Ensino e Aprendizagem.
} 
pela Nova Gestão Pública, com a intervenção de Ols, estão sendo elaboradas políticas supranacionais, internacionais ou transnacionais. Essas políticas têm sentidos diferenciados, indo desde a compreensão de que os problemas dos países não podem mais ser vistos de modo isolado (supranacional), passando pelo sentido de solidariedade e interculturalidade (internacional) e chegando à mercadorização pura e simples (transnacionalização) (AZEVEDO, 2015).

O fenômeno da globalização da educação tem representado várias concepções, tais como: a nova ordem educacional mundial (LAVAL; WEBBER, 2002); Agenda Globalmente Estruturada da Educação, AGEE (DALE, 2004); Internacionalização das Políticas Educacionais (AKKARI, 2011); Educação Global (BALL, 2020); Global Education Reform Moviment, GERM7 (SAHLBERG, 2012); Reformas empresariais mundiais de educação da Sociedade Mundial (VERGER, 2019); Redes de políticas internacionais de educação (SHIROMA, 2020).

A circulação mundial das ideias e políticas ocorre de várias formas. Uma delas consiste na elaboração de documentos contendo diretrizes e recomendações, feitas por Ols que circulam como orientações precisas a serem adotadas, após as devidas mediações. Em geral, os documentos de Ols vêm com a chancela das "evidências" resultantes de pesquisas realizadas. Também são adotados programas internacionais, como é o caso do Programa Internacional de Avaliação de Estudantes (PISA) que, ao fim e ao cabo, termina sendo o indicador de uma “educação de qualidade", levando a um processo de comparação internacional do nível educacional a partir dos resultados obtidos a cada três anos.

A face revelada da educação está assentada em uma Agenda Global, cuja semelhança tem levado a se falar em "migração de reformas", "políticas itinerantes" e “políticas viajantes”. Apesar das concepções sobre o papel da educação no processo da globalização neoliberal encaminharem para o sentido de uma Agenda Global, existem diferenças, por vezes sutis, mas importantes, entre as várias acepções desse fenômeno.

Laval e Webber (2002) anunciam que a globalização ou mundialização se caracteriza pelo domínio de um novo modelo de educação que é inspirado pela lógica

\footnotetext{
7 Movimento Global de Reforma da Educação.
} 
econômica do tipo liberal, constituindo-se em uma "nova ordem educacional mundial". Essa lógica introduz, no setor educacional, os mecanismos e os valores do mercado, dando destaque aos objetivos econômicos. Para esses autores, a Organização Mundial do Comércio (OMC), o BM, a OCDE e a Comissão Europeia (CE) são alguns think tanks que, de forma direta, definem as políticas educacionais. Para esses autores, os Ols têm contribuído para o estabelecimento dessa nova ordem mundial, propondo aos países a realização de reformas educacionais, lastreadas numa abordagem liberal e utilitarista, que tem o mercado como o definidor principal das políticas, considerando que a escola deve estar voltada para a formação do capital humano, ensinando as competências necessárias para tal. Tanto a OCDE, quanto o BM orientam as políticas educacionais no sentido da promoção de um ensino sob uma ótica econômica, aplicando os princípios da gestão empresarial e do financiamento, reduzindo o papel do Estado e ampliando a esfera do mercado.

Para Laval e Webber (2002), há, na atualidade, um novo modelo de educação, inspirado por uma lógica liberal que implantou uma nova ordem educacional mundial, cujas políticas, planos e ações devem corresponder às aspirações do mercado. Laval (2006) reforça a ideia apresentada, dizendo que a educação participa da globalização do mercado e é impulsionada por Ols, criando um modelo de escola que é menos nacional e cada vez mais mundial, menos público e mais híbrido (público e privado), obedecendo menos uma lógica estatal e mais a uma lógica de empresas, mais voltado às necessidades econômicas por meio das competências e menos à formação de uma cidadania cultural. Para o autor, essa nova ordem é representada por uma multinacionalização de estabelecimentos de ensino superior e educação básica, além da educação a distância e da venda de materiais educacionais. Além disso, para Laval (2006), o novo modelo relativiza algumas dimensões consideradas constitutivas da "antiga" escola, quais sejam, a integração cultural e a função política de formação do cidadão. Em revanche, a "nova" escola assume um papel econômico de formação de recursos humanos a serviço da eficácia econômica.

Dale (2004) desenvolveu a teoria da existência de uma Agenda Globalmente Estruturada da Educação (AGEE). Essa abordagem, segundo esse autor, considera a globalização como uma estratégia vigorosa de sustentação ao capitalismo, apoiada nas 
atividades econômicas, políticas e culturais de uma sociedade. Para a abordagem da AGEE, o capitalismo tem como objetivo central a busca do lucro, precisando para tal a formação de recursos humanos que possam contribuir para o cumprimento dessa “missão". Em função disso, essa agenda, que seria definida pelos Ols, vai priorizar a padronização da educação, cujo desempenho vai ser aferido por avaliações externas e em larga escala, devendo ser baseadas em um currículo, elegendo a matemática e a língua materna como a base do ensino. Para a realização desses propósitos, deve ser utilizado o modelo gerencial (NGP), empregando o estabelecimento de metas, a descentralização do processo, a accountability, que implica na responsabilização dos agentes escolares e na ênfase nos resultados. Dale (2004) faz, via AGEE, uma ligação direta entre as mudanças na economia mundial e as mudanças nas políticas e práticas educacionais. Para ele, "uma nova forma de força supranacional afeta os sistemas educativos nacionais" (DALE, 2004, p. 454).

A Internacionalização das Políticas Educacionais, analisada por Akkari (2011, p. 17), traz para reflexão o fato de que, na atualidade, "as políticas nacionais de Educação não podem mais ser concebidas e implementadas sem considerar os debates internacionais". Essa é uma realidade que envolve o mundo todo, fazendo circular padrões para a educação que acabam representando cópias malfeitas de modelos que, por sua vez, também não são originais. Em um trabalho analítico, Akkari (2011, p. 18) elenca temas que hoje fazem parte da nova vulgata educacional: adaptação à globalização econômica; benefícios das TIC para a educação; descentralização; privatização; obrigação de resultados; prestação de contas; boa governança; qualidade da educação; reformas curriculares; profissionalização docente.

A rapidez com que são transplantadas para outras realidades as políticas apregoadas pelos países centrais, via Ols e think tanks, sinaliza o que Akkari (2011) chama de movimentos planetários, tal a abrangência que alcançam e a adesão que recebem nas diferentes partes do mundo. Cria-se um marché scolaire (LESSARD; MEIRIEU, 2005), no qual tudo se vende em matéria de educação e tudo se compra, sob a rubrica de "boas práticas", de "ensino baseado em evidências", de "professores eficazes" e se vai vendendo a mercadoria educação em um mercado que está ávido por novidades que apresentem, com segurança, resultados. 
a uma padronização da educação que ocorre a partir dos anos 1990, cujas principais características se constituem em um currículo centralizado, avaliações externas, competição entre as escolas, responsabilização dos docentes que perdem sua autonomia. Para o autor, trata-se de uma Agenda Global que tem nos Ols o papel de difusor dessas políticas hegemônicas. Para Sahlberg,

\begin{abstract}
Uma coisa que me impressionou é como os sistemas de educação são semelhantes. Os currículos são padronizados para se adequar aos testes de estudantes internacionais; e alunos de todo o mundo estudam materiais de aprendizagem de provedores globais. As reformas educacionais em diferentes países também seguem padrões semelhantes. Essa forma comum de melhoria é tão visível que eu a chamo de Movimento de Reforma Educacional Global ou GERM. É como uma epidemia que se espalha e infecta os sistemas educacionais por meio de um vírus. Ele viaja com especialistas, mídia e políticos. Os sistemas de educação emprestam políticas de outros e são infectados. Como consequência, as escolas adoecem, os professores não se sentem bem e as crianças aprendem menos. (SAHLBERG, 2012, p. 2, tradução nossa) ${ }^{8}$
\end{abstract}

É interessante a comparação que Sahlberg (2012) faz do GERM, enquanto um movimento global, como um germe, um vírus, que circula pelo mundo por meio de algumas políticas que se tornaram padrão. Esse autor cita três "sintomas" de que o vírus está circulando no mundo: a competição entre as escolas, realizada pelos índices obtidos nos exames padronizados nacionais; a possibilidades de os pais escolherem, num leque de possibilidades, escolas para os filhos utilizando os vouchers; e, por último, como sinal de que o sistema educacional está infectado, aparece a responsabilização dos docentes pelos resultados obtidos pelos estudantes nos testes padronizados. Esse último sintoma do GERM, segundo o autor, realizou um estreitamento dos currículos, priorizando a leitura e a matemática.

\footnotetext{
8 One thing that has struck me is how similar education systems are. Curricula are standardized to fit to international student tests; and students around the world study learning materials from global providers. Education reforms in different countries also follow similar patterns. So visible is this common way of improvement that I call it the "Global Educational Reform Movement or GERM". It is like an epidemic that spreads and infects education systems through a virus. It travels with pundits, media and politicians. Education systems borrow policies from others and get infected. As a consequence, schools get ill, teachers don't feel well, and kids learn less (SAHLBERG, 2012, p. 2).
} 
Verger (2016) diz que os principais objetivos do GERM são aumentar a competitividade dos países, por meio, dentre outros fatores, da melhoria dos resultados escolares dos estudantes, para tanto, precisando tornar eficazes os sistemas educacionais. O autor exemplifica algumas políticas globais, cujo objetivo é alcançar a dita eficácia, sendo a descentralização, a responsabilização e a avaliação de professores os meios para tal. Para isso, é preciso adotar, nas escolas, os métodos de gestão e financiamento empresariais, a NGP, responsabilizando as escolas e recompensando ou penalizando os atores pelas performances apresentadas.

Ball (2020) também analisa a questão dessa Agenda. No livro Educação global S.A. Novas redes políticas e o imaginário neoliberal (2020), o autor afirma que "as redes políticas constituem uma nova forma de governança, embora não de uma forma única e coerente, e colocam em jogo, no processo de políticas, novas fontes de autoridade [...]" (BALL, 2020, p. 34). As redes citadas são compostas por atores diversos, o que dá espaço a novas vozes, se movimentando por toda a parte, apresentando uma ética maleável, que tem facilidade de atingir a população, por meio de redes políticas transnacionais.

As redes políticas analisadas por Ball (2020), na realidade, se constituem em uma nova governança da educação e podem ser compostas por empresas, por ações de filantropia de organizações que prestam serviços para a educação, por políticas educacionais elaboradas pelo Estado, por organizações intergovernamentais como o BM, a OCDE, a OMC, corporações transnacionais e Organizações Não Governamentais (ONGs). Ou seja, um complexo de instituições, entidades e organizações que se unem, em determinados momentos, para estabelecerem políticas e organizarem sua transferência. Com isso, Ball alerta para o fato de que "as fronteiras entre o Estado, a economia e a sociedade civil estão ficando turvas, há novas vozes nas conversas sobre as políticas e novos canais por meio dos quais os discursos sobre políticas introduzem o pensamento sobre políticas" (BALL, 2020, p. 34).

Shiroma (2020) fala das redes de políticas públicas regionais, cujo objetivo é promover o alinhamento das agendas internacionais e locais em uma espécie de “empréstimo de políticas" ou policy transfer ou, ainda, migração de reformas (SHIROMA, 2020, p. 2). Segundo a autora, essas redes de políticas públicas são as responsáveis pela semelhança das reformas, realizando o alinhamento de agendas no mundo. Fica evidente 
na análise feita por Shiroma (2020) que o objetivo das redes é difundir medidas que atendam às demandas postas pelo capital, a fim de garantir a acumulação, sendo a educação uma ferramenta importante para esse fim na medida em que forma a força de trabalho que pode contribuir para a expansividade do capital. É importante dizer que as "redes de governança reúnem representantes de agências multilaterais, governos nacionais, organizações sociais, think tanks, empreendedores sociais e corporações multinacionais" (SHIROMA, 2020, p. 6). O papel desse mecanismo seria o de servir como “alternativa política para as ‘ineficiências’ do Estado” (SHIROMA, 2020, p. 6).

A Agenda Global se efetiva por meio de Ols e de redes transnacionais, difundindo o que Oliveira (2020, p. 87) chama de políticas itinerantes. Esse tipo de política representa o "movimento de circulação ou mobilidade das políticas em âmbito mundial”, sendo os "conceitos que circulam em reformas educacionais e propostas curriculares em nível internacional" considerados "resultados dos processos de globalização" (OLIVEIRA, 2020, p. 87).

Verger (2019) também aborda a questão das "políticas viajantes" ao referir-se a ações semelhantes presentes em várias partes do mundo, sendo por isso chamadas de políticas educacionais globais. Mas este autor (VERGER, 2019) chama a atenção para uma questão importante e, por vezes, esquecida: as políticas educacionais globais sofrem alterações nessas "viagens". Tem-se que considerar as peculiaridades, as políticas locais e o papel que desempenham os atores nativos. Não há uma mera transposição, existe uma cultura que se impõe e que modifica, adapta e molda os "pacotes" recebidos. São aspectos que precisam ser considerados. Apesar da tentativa de harmonização que essas "políticas viajantes" ou itinerantes representam e da tentativa de implantação à semelhança do modelo, há um espaço de manobra que, mesmo guardando a espinha dorsal das ideias centrais, permite um amoldamento aos costumes locais, sem perda do essencial que é o processo de sustentação e expansão da globalização neoliberal como arcabouço de sustentação do capital.

A existência dessa Agenda Global da Educação, movimentada principalmente, mas não só, por Ols, teve um protagonismo no momento da crise sanitária provocada pelo Sars-CoV-2. Organizações Internacionais como o BM, a OCDE e a Unesco produziram 
pesquisas, análises e documentos que contêm diretrizes, estratégias para orientar os países no processo educacional que foi duramente atingido pela pandemia.

A segunda parte do texto trata desse aspecto, procurando manter a relação entre a Agenda Global da Educação e as medidas educacionais propostas durante e para o depois da Covid-19.

\section{A Agenda Global da Educação na pandemia}

O Banco Mundial publicou um documento intitulado The Human Capital Index 2020 UPDATE Human Capital in the Time of COVID-19 ${ }^{9}$ (ICH) (2020a) no qual são apresentados os resultados dos últimos anos, de cerca de 170 países, em relação ao desenvolvimento econômico e social. O ICH é uma métrica internacional, instituída por esse OI, cujo objetivo é avaliar os conhecimentos, as habilidades e a saúde que as pessoas acumulam ao longo da vida, sendo considerados um condutor do crescimento econômico e da redução da pobreza.

O documento do BM foi elaborado no início da pandemia, em março de 2020, e por isso apresenta o resultado de uma simulação realizada que indicava que o fechamento de escolas, combinado com dificuldades familiares, afetaria a acumulação do capital humano para a geração atual de crianças em idade escolar. Isso porque, para essa organização, o índice mede o capital humano de uma criança a partir do nascimento até a idade de 18 anos, considerada fase produtiva, levando-se em conta a expectativa de anos de escolaridade e as notas obtidas em testes internacionais, do tipo PISA.

Com esses dados, o Banco Mundial faz um alerta para o fato de que essa situação ameaça os avanços alcançados em relação ao capital humano $(\mathrm{CH})$ e por isso era preciso proteger os avanços conquistados, chamando a atenção para a seriedade do fato e da necessidade do desenvolvimento de ações que pudessem minorar a situação.

Em outro documento, Proteger pessoas e economias, respostas de políticas integradas à Covid-19, o Banco Mundial (2020b) alertou para o fato de que essa pandemia se tornou uma crise econômica internacional, podendo ampliar as desigualdades. Há um reconhecimento da letalidade do vírus e, ao mesmo tempo, um alerta para o caso da

\footnotetext{
${ }^{9}$ Atualização do Índice de Capital Humano 2020: Capital Humano na Época da Covid-19.
} 
adoção de medidas drásticas, o que poderia levar a uma recessão econômica, trazendo fortes rebatimentos sobre o capital humano. O capítulo 3 desse documento traz orientações muito detalhadas para manter a aprendizagem dos alunos, ao mesmo tempo, que se deve proteger a saúde e a segurança dessa população. O documento alertava para o fato de que, na ausência de políticas de enfrentamento ao vírus, "os resultados da aprendizagem dos alunos serão provavelmente afetados negativamente, com potenciais consequências ao longo prazo para sua realização, empregabilidade, produtividade e bem-estar" (BANCO MUNDIAL, 2020b, p. 34). Com essa certeza, o OI recomendava que os governos agissem e desenvolvessem três tipos de políticas, que incluem a proteção dos alunos durante o período de fechamento das escolas, propiciando uma "aprendizagem equitativa"; outra medida apontada relaciona-se à reabertura das escolas "com a menor perda de aprendizagem possível"; e "políticas de melhoramento e aceleração, para que a educação não se limite a voltar aos padrões problemáticos pré-Covid" (BANCO MUNDIAL, 2020b, p. 34).

A ênfase, nos dois documentos citados, é na necessidade de preservação do capital humano, o que é importante, contudo, insuficiente, tendo em vista que não há, de forma explícita, uma marcação do BM a medidas relativas à preservação das vidas. Mas, sabe-se que em uma sociedade capitalista, o objetivo maior é a expansividade do capital, o aumento da acumulação, a garantia dos lucros e a lógica do capital humano.

Ao analisar a concepção de $\operatorname{Schultz}^{10}$ (1973, p. 39) sobre a Teoria do Capital Humano $(\mathrm{TCH})$, que defende que há um nexo entre os avanços educacionais e o crescimento econômico de um país, Frigotto diz que

O método em que ela $[\mathrm{TCH}]$ se funda e desenvolve na análise do real traduz e, [...] constitui-se em apologia da concepção burguesa de homem, de sociedade, e das relações que os homens estabelecem para gerar sua existência no modo de produção capitalista. (FRIGOTTO, 2006, p. 52)

Oliveira (2020) analisa também a Teoria do Capital Humano, destacando que Schultz (1973) vê a educação como uma forma de investimento, ampliando o conceito de

\footnotetext{
10 Theodore Schultz é considerado o "pai" da Teoria do Capital Humano, economista norte-americano, tendo recebido o Prêmio Nobel de Economia em 1979 pelos estudos sobre o papel do capital humano no crescimento econômico.
} 
capital que era restrito a equipamento e patrimônio. Essa autora aponta o papel que alguns Ols, no caso específico a OCDE, têm na promoção dessa teoria e exemplifica como o PISA desempenha esse papel. Para Oliveira, este exame internacional

tem de ser compreendido e analisado dentro do contexto mais amplo que o gerou: as relações de poder em âmbito mundial que apelam a modos específicos de regulação que expressam uma determinada concepção de educação cuja matriz é a teoria do capital humano. (OLIVEIRA, 2020, p. 82)

O que está explicitado nos dois documentos do BM, The Human Capital Index 2020 UPDATE (2020a) e Proteger pessoas e economias, respostas de políticas integradas à Covid19 (2020b), é assentado na Teoria do Capital Humano, ou seja, no interesse em "salvar" a educação como investimento importante para o crescimento econômico.

Ainda, o Banco Mundial (2020c), em documento datado de maio de 2020, traz uma avaliação da situação educacional no mundo causada pelo vírus e apresenta propostas para sua saída, indicando, comme il faut, que é preciso ver em tudo isso uma "janela de oportunidades" e saber aproveitá-las. Há uma preocupação expressa em relação às repercussões que essa crise sanitária trará sobre a educação, sobretudo, em função do fechamento das escolas e da anunciada recessão que o mundo viverá como consequência da crise econômica que virá decorrente da pandemia.

O Banco Mundial, que manifestou a inquietude com a perda de produtividade do capital humano, fez outras análises relacionadas à Covid-19 e às perdas na educação. Esse organismo (2020c) parte da premissa de que, antes da pandemia, o mundo atravessava uma crise de aprendizagem, lembrando o compromisso do Objetivo do Desenvolvimento Sustentável (ODS) que indica que, até 2030, todos devem ter assegurado uma educação de qualidade e ter possibilidades de garantir uma aprendizagem ao longo da vida. $\mathrm{O}$ Índice de Pobreza de Aprendizagem, elaborado pelo Banco, indica que 53\% das crianças de até 10 anos, em países de baixa ou média renda, não sabem ler, nem compreendem um texto simples. Mas essa situação atinge também o ensino superior, cujas atividades de ensino e pesquisa pararam. O documento informa que, a partir de abril de 2020, as instituições de ensino superior fecharam suas portas em 175 países e mais de 220 milhões de estudantes, nesse nível de ensino, tiveram seus estudos interrompidos. 
Há, por parte do BM, uma preocupação no sentido de que medidas urgentes e importantes precisam ser tomadas para evitar que os países sofram perdas, a longo prazo, em matéria de educação e de capital humano. Algumas consequências apontadas indicam que essa crise sanitária, que levou ao fechamento das escolas, no futuro, produza resultados nefastos, tais como aumento das desigualdades sociais, diminuição do capital humano e reforço do ciclo intergeracional de pobreza.

Uma meta proposta pelo BANCO MUNDIAL (2020c, p. 7) é "aproveitar as oportunidades para tornar a educação mais inclusiva, eficaz e resiliente do que era antes da crise". Para tanto, o receituário é apresentado, devendo os países saberem, em primeiro lugar, "lidar com a situação", protegendo a saúde, a segurança e a nutrição dos estudantes, evitando a perda da aprendizagem por meio do ensino remoto e alavancando a educação terciária. A medida número 2 refere-se a saber "gerir a continuidade", evitando a evasão, avaliando as perdas de aprendizagem, promovendo a melhoria e aceleração do ensino. Finalmente, a etapa de número 3 se refere à "melhoria e aceleração", apresentando "abordagens eficazes de resposta ao COVID” (BANCO MUNDIAL, 2020c, p. 7), incorporando o ensino remoto. Tal recomendação é novamente enfatizada pelo BM quando discute o perfil da escola de amanhã e reforça que "a pandemia abre um novo horizonte, onde os esperados investimentos em tecnologia, professores, pais e comunidades podem ser feitos mais rapidamente e otimizados" (BANCO MUNDIAL, 2021a, p. 10, tradução nossa)"11. Uma posição conhecida dessa organização é aquela que indica que os países podem tirar muitas lições desse momento e aproveitar essa janela de oportunidades.

Fernando Reimers, da Global Education Innovation Initiative, Harvard Graduate School of Education (GEI) e Andreas Schleicher, da Directorate of Education and Skills, da Organização para Cooperação e Desenvolvimento Econômico (OCDE), elaboraram, em março de 2020, um documento denominado Um roteiro para guiar a resposta educacional à Pandemia da COVID-19 (REIMERS; SCHLEICHER, 2020a). Esse "roteiro" foi construído a partir de uma pesquisa realizada em 98 países $^{12}$, cujos participantes ${ }^{13}, 330$, responderam a

\footnotetext{
${ }^{11}[. .$.$] la pandémie ouvre um horizon inédit, où les investissements attendus depuis longtemps dans la$ tecnologie, les enseigants, les parentes et les communautés pourraient être réalisés plus rapidement et optimisés (BANCO MUNDIAL, 2021a, p. 10).

${ }^{12} \mathrm{O}$ Brasil fez parte da pesquisa com três respondentes, mas não há informação de quem foram os
} 
um questionário online sobre os desafios e as reações impostos pela Covid-19 e os recursos utilizados para o enfrentamento a esse vírus. Com base nas respostas, o documento foi preparado para orientar as estratégias de educação no contexto pandêmico.

O documento elaborado por integrantes da OCDE-GEI traz um checklist de atividades que deveriam ser desenvolvidas relativas ao setor educacional. Em 11 de março de 2020, a Organização Mundial da Saúde elevou ao estado de pandemia, o que antes era estado de contaminação, a doença da Covid-19, causada pelo vírus Sars-CoV-2. O checklist é datado de 30 de março do mesmo ano, ou seja, no início da crise sanitária que dura mais de 12 meses.

Nesse rol de recomendações, 25 no total, ganham relevo as referentes à necessidade de uma coordenação da crise, que envolve a criação de comitê, definição de princípios norteadores, cronograma e mecanismos de ação. Um outro grupo de recomendações ou de estratégias traçadas envolve mais diretamente as questões pedagógicas, tais como a revisão dos objetivos curriculares, identificação dos meios de ensino mais viáveis para as circunstâncias, a busca de diferentes estratégias para o processo ensino-aprendizagem ${ }^{14}$, indo desde o ensino online, ampliando o leque que inclui televisão, podcasts, programas de rádio, pacotes de ensino digital ou em papel.

Houve, no roteiro, a atenção sobre os docentes, sendo indicado que deveria ser criado um mecanismo de formação contínua de emergência, preparando os professores para a nova modalidade de ensino. A questão dos alunos foi contemplada, dentre outras estratégias, pela recomendação de definir mecanismos apropriados de avalição para esse período e, consequentemente, mecanismos de aprovação e conclusão.

Além do checklist, o documento traz 15 recomendações que deverão ser observadas pelo setor educacional nesse momento de pandemia. Dentre elas, realçamos a postura proativa que os líderes educacionais, ministros, dirigentes em diferentes níveis

\footnotetext{
participantes.

13 Os respondentes podiam ser docentes da educação básica e educação superior, técnicos, diretores, secretários de educação, ONG com foco em educação, pessoal do Ministério da Educação, redes privadas, organizações internacionais, consultores educacionais.

${ }^{14}$ Em todo o mundo, a maioria das escolas, de todos os níveis e etapas, fechou suas portas em março de 2020.
} 
devem adotar para "prevenir a perda de aprendizagem durante o período de distanciamento social necessário", além de contribuírem "para a criação de oportunidades para ajudar a requalificar os deslocados de seus empregos pela pandemia e facilitar sua reintegração no mercado de trabalho" (REIMERS; SCHLEICHER, 2020a, p. 12). Recomenda-se uma "reorientação das metas curriculares e a definição do que deve ser aprendido durante o período de distanciamento social” (SCHLEICHER, 2020a, p. 8), havendo uma indicação de que as escolas possam ter acesso a planos desenvolvidos por outros estabelecimentos de ensino.

O documento Um roteiro para guiar a resposta educacional à Pandemia da COVID-19 (REIMERS; SCHLEICHER, 2020a) procurou, ainda no início da pandemia, trazer orientações para a educação no sentido de adotar medidas-padrão que favorecessem o processo de ensino em diferentes partes do mundo. É preciso considerar a diferença entre os países, visível no próprio documento em questão, devendo-se levar em consideração as peculiaridades e as questões estruturais, não sendo possível haver uma padronização das ações.

Em maio de 2020, Reimers e Schleicher (2020b) publicam um novo documento intitulado Educação interrompida, Educação repensada: como a pandemia da Covid-19 está mudando a educação, resultado de uma segunda pesquisa realizada pelas mesmas organizações, OCDE e GEI, abrangendo 59 países e 1370 respondentes. Com um espaço de quase três meses entre as duas enquetes, a última foi realizada em um momento no qual havia uma previsão de que as escolas começariam um processo de reabertura, o que na realidade ocorreu parcialmente em alguns países em função de uma segunda onda de propagação do vírus. O documento (REIMERS; SCHLEICHER, 2020b) apresenta "duas lições" aprendidas no período no qual as escolas tiveram que fechar. A primeira delas se refere às desigualdades sociais reveladas pela pandemia, no tocante ao acesso à tecnologia, à banda larga, ao conhecimento e à utilização das tecnologias de informação. A segunda lição, segundo as organizações que realizaram a pesquisa, refere-se ao acesso que os professores têm à tecnologia e à capacidade de envolvimento em múltiplas plataformas.

Seguindo o modelo da pesquisa anterior, realizada em março de 2020, as organizações fizeram um checklist "para sustentar a continuidade da educação na 
segunda fase da pandemia" (REIMERS; SCHLEICHER, 2020b, p. 11), relacionando 15 itens a serem observados para o retorno ao presencial. São, na realidade, recomendações de cuidados relativos à higiene, ao distanciamento social, ao uso de álcool gel, o chamado protocolo sanitário, além de aspectos pedagógicos que envolvem o currículo, a avaliação, o preparo dos professores, dentre outros.

Chama a atenção no checklist, o item 7, mas igualmente ao longo do documento, a indicação do ensino híbrido como o "novo normal”. Há uma forte recomendação, naquele momento, maio de 2020, ainda de um modo discreto, da introdução dessa nova “modalidade" de ensino no pós-pandemia. Assim, observa-se a insinuação da questão, como a avaliação de que "é provável que uma porção importante do tempo de aprendizado permaneça online" (REIMERS; SCHLEICHER, 2020b, p. 12) ou a recomendação de que "os planos de reabertura também preveem a aquisição de dispositivos para alunos e professores, para apoiar a aprendizagem online no futuro, investimento na criação de plataformas eficazes de aprendizagem online" (REIMERS; SCHLEICHER, 2020b, p. 36). Sugere-se ademais que se ouçam os alunos, avaliando a experiência vivida, fazendo um balanço de como as escolas se adaptaram à situação "e [é preciso] incluir seus pontos de vista no formato de um novo ecossistema híbrido e expandido para a aprendizagem" (REIMERS; SCHLEICHER, 2020b, p. 14).

O documento Regards sur l'éducation 2020 Les Indicateurs de l'OCDE'15 (OCDE, 2020a), publicação anual desse organismo, divulgado em setembro de 2020, trouxe, nessa edição, um apêndice intitulado El impacto del COVID-19 em la educacion. Información del Panorama de la Educación 2020 (OCDE, 2020b). Um dos pontos destacados nesse documento é a questão do financiamento, tendo em vista que a crise sanitária levou ao fechamento não somente das escolas, mas da economia em geral, o que acabou provocando uma crise financeira. Alguns dados apontados são graves, pois indicam a possibilidade de uma grande recessão no mundo e, consequentemente, a redução do financiamento público para a educação. Um dos pontos levantados pelo documento trata do ensino a distância que foi o grande apoio no período de fechamento das escolas, demarcando-se que essa modalidade digital de ensino oferece muito mais do que uma

\footnotetext{
${ }^{15}$ É um documento publicado anualmente e tem como objetivos apresentar, por meio de indicadores de recursos humanos e financeiros mobilizados pelos governos, a evolução dos sistemas educacionais em escala internacional, com fins de comparação.
} 
solução emergencial, podendo-se descortinar, a partir dessa experiência, um mundo novo em matéria de aprendizagem e, como tal, deve continuar sendo utilizada. Mas o documento chama a atenção para o despreparo dos docentes em relação à utilização da tecnologia de informação e a necessidade de prepará-los para situações futuras.

Outra organização internacional que também vem produzindo documentos, reuniões e orientações relacionadas à educação no período da pandemia é a Organização das Nações Unidas para a Educação, a Ciência e a Cultura (Unesco) que, desde o início da crise sanitária, mostrou-se atenta ao desdobramento da questão, tendo em vista a amplitude que essa tomou, na medida em que atingiu cerca de 190 países e mais de 1 bilhão e 600 milhões de estudantes em todo o planeta. Essa crise é considerada a mais grave dos últimos cem anos. Em função desses fatos, a organização vem desenvolvendo diferentes ações que podem ajudar a minorar os efeitos perversos aportados pela Covid19, sobretudo no setor educacional. Uma das grandes preocupações da Unesco tem sido a perda da qualidade da educação, afetando os Objetivos do Desenvolvimento Sustentável 2030 (ODS), com destaque à meta 4, que serve como baliza para a implantação de uma educação equitativa e inclusiva. A Covid-19 é uma ameaça real para que isso seja provável (UNESCO, 2020a).

As análises feitas pela Unesco levam em consideração vários aspectos, dos quais salientam-se alguns. O financiamento tem sido o carro chefe dentre as apreensões dessa organização. E partindo da premissa de que havia um déficit orçamentário em relação a essa política pública, a pandemia aprofundou a questão. Houve uma diminuição das receitas e a composição do produto interno bruto teve uma queda sensível, sobretudo nos países menos desenvolvidos, levando a um aumento dos níveis de endividamento público, o que, por consequência, levaria a uma diminuição dos recursos destinados à educação. Há clareza de que esse processo de diminuição de recursos para a educação vinha sofrendo uma retração. Ou seja, a pandemia não criou o problema, mas o aprofundou grandemente e, pelas análises feitas, os recursos destinados à educação poderão atingir o nível de 2018 somente em 2024 (UNESCO, 2020b, p. 12).

Segundo estudos realizados pela Unesco (2020b), houve um aumento da desigualdade social no período pandêmico. No segundo trimestre de 2020, as estatísticas apontavam que $86 \%$ dos alunos de países menos favorecidos não estavam tendo nenhum 
atendimento educacional, presencial ou a distância, enquanto nos países ricos esse número era de $20 \%$. O fato pode estar ligado à capacidade dos países de propiciarem aos estudantes e aos professores o material necessário para o desenvolvimento de um ensino remoto, o que exige internet de boa qualidade, dados móveis disponíveis, aparelhos como notebook, tablet ou mesmo telefone celular que permitissem a essa população ter acesso às aulas. É importante ressaltar que a Unesco propugna por plataformas digitais públicas, o que não somente deixaria de onerar o usuário, como, e principalmente, daria autonomia e independência às instituições educacionais para elaborarem suas próprias programações, devendo os países investir em infraestrutura e na pressão para que os custos de acesso às redes digitais tenham um valor mais justo (UNESCO, 2020b).

A Unesco, semelhante ao BM e à OCDE, defende um ensino híbrido, pelas plataformas nacionais e internacionais, com recursos pedagógicos alternativos e presencial nas escolas. O hibridismo defendido pela Unesco é amplo, tendo em vista que inclui estruturas educativas formais e não formais e aí é preciso criar critérios de validação desses conhecimentos para fins de acreditação curricular (UNESCO, 2020d).

Enquanto a possibilidade da abertura das escolas é incerta e desigual, a organização centra suas ações no sentido de garantir o financiamento da educação, na defesa de que esta tem um papel poderoso e eficaz na retomada econômica a curto prazo e no desenvolvimento e transformação durável a longo prazo. A Unesco (2020d) mostra certa ansiedade no que toca à redução do financiamento interno feito pelos governos, em função da diminuição do PIB, e da ajuda internacional. Isso poderia aumentar a crise da educação existente e provocar o abandono de milhões de crianças das salas de aula, diminuindo as chances de empregabilidade futura.

É com esse espírito que, em março de 2020, quando a pandemia começava a se alastrar, a Unesco criou a Coalizão Global de Educação, "uma parceria multisetorial para atender à urgente necessidade mundial de continuidade da educação em uma escala sem precedentes" (UNESCO, 2020c, p. 1), oferecendo aos países membros uma ajuda para fazer face aos desafios da pandemia. Essa coalizão reúne-se em torno de um objetivo comum, qual seja, a garantia da educação para todos e é constituída por membros da ONU, cerca de 150 entidades, sociedade civil, universidades, setor privado. A Coalizão realizou uma reunião paralela à $75^{\mathrm{a}}$ sessão da Organização das Nações Unidas (ONU), em 
setembro de 2020, objetivando chamar a atenção ao grave problema presente e futuro que paira sobre o processo educacional em todo o mundo, chamado de catástrofe geracional, tendo em vista suas consequências em toda uma geração que está na atualidade nos sistemas educacionais.

Um outro fato que merece atenção é que a Unesco organizou, em outubro de 2020, uma Reunião [extraordinária] Mundial de Educação (Global Education Meeting GEM), com a coorganização dos governos de Gana, da Noruega e do Reino Unido. A reunião teve como objetivo central discutir algumas ações importantes para garantir o financiamento nacional e internacional da educação; a abertura das escolas com toda a segurança sanitária; o apoio à inclusão, equidade e igualdade de gênero; a reinvenção do ensino e da aprendizagem; a exploração de uma conectividade e tecnologias com equidade.

A Declaração da Reunião Mundial de Educação 2020 (UNESCO, 2020d) expressa os compromissos assumidos pelos países participantes e está em sintonia com o momento no qual o mundo vive em relação à Covid-19. Houve um compromisso de

[...] aumentar ou manter a parcela do gasto público em educação em relação aos referenciais internacionais de pelo menos $5 \%$ a $6 \%$ do PIB e/ou $15 \%$ a $20 \%$ das despesas públicas; [...] reabrir com seguranças as instituições educacionais, com base em evidências científicas e considerando os contextos locais; [...] priorizar a saúde e a segurança de estudantes e educadores por meio de uma colaboração intersetorial mais estreita; [...] apoiar todos os docentes e pessoal da educação como trabalhadores da linha de frente, consultando seus representantes na tomada de decisões e garantindo sua segurança, seu bem-estar; [...] reduzir a exclusão digital na educação, desenvolver recursos educacionais abertos (REA) de qualidade e construir bens comuns digitais como um complemento à aprendizagem presencial, com vistas a permitir a aprendizagem inclusiva e equitativa apoiada pela tecnologia (UNESCO, 2020d)

A Declaração encerra com um compromisso formal de monitorar esses pontos, nos próximos 15 meses (até dezembro de 2021) e relatar os resultados na próxima reunião da entidade.

No Dia Internacional da Educação, 25 de janeiro de 2021, a ONU, em Assembleia Geral, elegeu como tema para esta terceira edição, "Recuperar e Revitalizar a Educação 
para a Geração COVID-19"16. O documento orientador das atividades relativas a essa

efeméride, elaborado pela Unesco (2021), pontua que pelo menos $1 / 3$ dos alunos do mundo não foram capazes de acessar a aprendizagem remota. Por isso, salientou que é preciso “dar voz à geração COVID-19 para expressar suas preocupações e aspirações em face de um futuro marcado por uma recessão econômica e mudanças climáticas" (UNESCO, 2021, p. 2, tradução nossa) $)^{17}$.

\section{Considerações finais}

A globalização da economia e as novas tecnologias digitais têm ampliado as possibilidades de relações planetárias, fortalecendo o capitalismo e alargando seu raio de ação na busca de lucros e da acumulação. Nesse contexto, o papel de organismos internacionais se estendeu e se fortificou, tornando-os grandes responsáveis pela elaboração de diretrizes, estratégias e orientações de políticas referentes a variadas áreas, sejam econômicas, políticas ou sociais. O neoliberalismo, corolário da globalização, exerce pressão transnacional no sentido de liberar a atividade econômica da regulação do Estado, tendo o cuidado de não anular o papel necessário que esse ente deve exercer para a lógica expansionista da acumulação. Para atingir esses objetivos, o mercado e o Estado firmam parcerias que funcionam como redes que impulsionam o estabelecimento de políticas e o desenvolvimento de ações que atendam à lógica mercantilista.

Nessa cadeia de ações, a educação, na perspectiva da Teoria do Capital Humano, representa um elo importante que deve ser dirigido para formação de uma mão de obra baseada em competências e habilidades que permitam a movimentação da cadeia produtiva, a produção de mais valor, sem as garantias ao trabalhador de políticas de segurança e proteção aos direitos básicos e fundamentais do ser humano, que vão além da reprodução da força produtiva. Por isso, a constituição de uma Agenda Global da Educação passou a ser fundamental e os OI, empresas, think tanks, organizações não governamentais, entidades filantrópicas têm procurado assumir as funções de um ministério mundial da educação (LEHER, 1999), elaborando a Agenda Global da Educação.

\footnotetext{
${ }^{16}$ Recover and Revitalize Education for the COVID-19 Generation (UNESCO, 2021).

${ }_{17}$ Give voice to the COVID-19 generation to express their concerns and aspirations in the face of a future marked by an economic recession and climate change (UNESCO, 2021, p. 2).
} 
As políticas públicas educacionais nacionais, com as devidas mediações, passam a ser elaboradas baseadas nos objetivos e metas da Agenda Global da Educação, cujo objetivo principal é garantir ao capital que realize o circuito que promova a acumulação por meio da formação do capital humano. Por isso, é importante estabelecer essas relações entre as finalidades dessa agenda, elaborada pelos representantes da globalização neoliberal, e o que é apresentado como demanda da sociedade. A falta dessa ligação torna as análises ingênuas e desprovidas de caráter político, responsabilizando apenas o mensageiro (que também não é inocente), que é o governo de plantão, pela aprovação e implantação de determinadas medidas.

Os OI analisados neste artigo, BM, OCDE e UNESCO, mantêm uma linha comum dentro dessa Agenda Global da Educação que, durante a pandemia da Covid-19, se evidenciou pelo funcionamento do sistema educacional, mesmo que a distância, para tentar diminuir os fortes impactos sobre a formação do capital humano. Para tanto, algumas medidas foram/são propostas, sobressaindo-se as relacionadas ao financiamento da educação. Mas há um sentimento comum entre os Ol que é a perda significativa da aprendizagem, nesse período, para os países mais pobres e um aumento das desigualdades que existiam antes da pandemia.

É importante considerar a posição da OCDE (2021), expressa no documento Positive, High-achieving Students? What Schools and Teachers Can Do ${ }^{18}$, que apresenta os dados coletados em nove países, por meio do projeto Talis-PISA, realizado em 2018. As análises das informações obtidas indicam que os professores não são e não podem ser substituídos pelas tecnologias da educação, destacando o papel determinante dos docentes e das escolas para aprendizagem social, emocional e cognitiva dos estudantes, aumentando o interesse pela escola, ampliando as aspirações de vida e o autoconceito. E mais, a pesquisa demonstra que a maioria dos pais passaram a desenvolver um respeito pelo trabalho realizado pelos professores em sala, enquanto os alunos informaram que sentem falta do processo ensino-aprendizagem presencial.

As análises podem ser importantes para o processo educacional pós-pandemia, reforçando o significado do ensino presencial com as interações sociais estabelecidas, sublinhando-se o significado do trabalho docente, das tecnologias digitais, mas

\footnotetext{
${ }^{18}$ Alunos positivos e de alto desempenho? O que escolas e professores podem fazer?.
} 
enfatizando que estas são ferramentas importantes, porém complementares na relação educacional, devendo ser utilizadas, sem, contudo, significar que devam substituir grande parte do trabalho do profissional da educação. Ou seja, o ensino híbrido, que vem sendo apontado por OI como o futuro da educação pós-pandemia, precisa ser visto dentro de um ângulo diferente.

O BM em um documento com o título sugestivo, Agindo agora para proteger o capital humano de nossas crianças. Os custos e a resposta ao impacto da pandemia de COVID-19 no Setor de Educação na América Latina e Caribe (2021b), aponta que a pandemia impôs perdas de aprendizagem nunca vistas em uma geração e que é preciso envidar esforços para fazer frente a esse imenso desafio. O documento citado trata da "pobreza de aprendizagem" da região e traz dados alarmantes, enfatizando-se que havia uma decalagem nesse processo antes da catástrofe provocada pelo SARS-CoV-2, quando na região da América Latina e Caribe dois em três estudantes do ensino fundamental não conseguiam ler um texto curto e, segundo projeções desse Ol, cerca de $71 \%$ dos estudantes poderão não atingir os níveis mínimos de proficiência, adotados pelo PISA nos próximos anos.

Não há dúvida de que a situação é avassaladora e medidas urgentes precisam ser tomadas pelos governos para diminuir os efeitos dessa tragédia. A questão do financiamento da educação é um dos elementos-chave que deverá ser acionado para fazer face às necessidades impostas para a recuperação do setor educacional. Sabe-se que a maioria dos países manteve o ensino remoto na grande parte do tempo em que as escolas estiveram fechadas. Mas os resultados evidenciam que o ensino presencial é fundamental e a indicação feita da adoção do ensino remoto não irá possibilitar que se minimizem as perdas da aprendizagem ocorridas. As pesquisas têm mostrado que falta infraestrutura para que os estudantes possam ter aulas remotas.

Outro aspecto refere-se à constatação do BANCO MUNDIAL (2021b) em relação aos “prejuízos na aprendizagem” e ao custo econômico. Para essa instituição, pode haver uma perda de ganhos de 1,7 trilhão de dólares para os 10 meses de escolas fechadas, representando uma perda de capital humano e produtividade.

A Agenda Global da Educação teve um reforço importante no período da pandemia, momento no qual os países estavam fragilizados pela devastação que a Covid- 
19 vem causando. O protagonismo de Ol foi otimizado e, em alguns casos, tornou-se o principal ator na indicação de rumos relativos ao setor educacional. É importante assinalar que os elos estabelecidos entre os governos e os $\mathrm{Ol}$ se aprofundaram nesse momento da crise sanitária e as orientações e diretrizes emanadas no período podem se tornar o principal receituário a ser seguido pelos governos nacionais, sobretudo se isso significar a possibilidade de um aporte financeiro para a implementação das diretrizes sugeridas.

Destaque-se a possibilidade de se instituir, doravante, um ensino híbrido, no qual os estudantes possam ir à escola alguns dias por semana e o restante do tempo permanecerem com o ensino a distância. Essa é uma insinuação feita pelos organismos analisados neste trabalho e deve ser um motivo de preocupação por todas e todos que defendem uma educação de qualidade social, gratuita e laica. O Secretário Geral da Organização das Nações Unidas é muito enfático a respeito do assunto; para ele, "neste momento crucial, estou pedindo a todos os países que usem a recuperação para reduzir as divisões educacionais, expandir a conectividade digital e reimaginar a educação" (ONU, 2021).

A título de conclusão, evidencie-se que em momentos de tragédia, como a que o mundo viveu/vive, ocasionada pela Covid-19, o mais importante é proteger vidas, pois sem elas não haverá o tal do capital humano. Por isso, a Agenda Global da Educação tem essa tarefa difícil, em uma sociedade capitalista; lutar para que os trabalhadores não morram, afinal eles e elas se constituem em uma força produtiva, e ao mesmo tempo, defender uma educação cuja base é a Teoria do Capital Humano.

\section{Referências}

AKKARI, Abdeljalil. Internacionalização das políticas educacionais: transformações e desafios. Petrópolis: Editora Vozes, 2011.

AZEVEDO, Mário. Internacionalização ou transnacionalização da educação superior: entre a formação de um campo social global e um mercado de ensino mundializado. Crítica Educativa, Sorocaba, v. 1, n. 1, p. 56-75, jan./jun. 2015.

BALL, Stephen. Educação Global S.A: novas redes políticas e o imaginário neoliberal. Ponta Grossa: UEPG, 2020. 
BANCO MUNDIAL. La enseñanza superior: lecciones derivadas de la experiencia. Washington: World Bank, 1995. Disponível em: http://documents1.worldbank.org/curated/en/274211468321262162/pdf/13350oPAPERoSp1r ioroBox2150A1995001.pdf. Acesso em: 03 fev. 2021.

BANCO MUNDIAL. Prioridades y estrategias para la educación. Washington: World Bank, 1996. Disponível em:

http://documents1.worldbank.org/curated/en/715681468329483128/pdf/14948010spanish. pdf. Acesso em: 01 fev. 2021.

BANCO MUNDIAL. The human capital index 2020 update: human capital in the time of COVID-19. [Washington]: BANCO MUNDIAL, 2020a. Disponível em: https://reliefweb.int/sites/reliefweb.int/files/resources/152967.pdf. Acesso em: 04 jan. 2021.

BANCO MUNDIAL. Proteger as pessoas e as economias: respostas políticas integradas à COVID- 19. [Washington]: BANCO MUNDIAL,2020b. Disponível em: https://olc.worldbank.org/system/files/\%28Portugu\%C3\%AAs\%29\%20Protecting-People-andEconomies-Integrated-Policy-Responses-to-COVID-19.pdf. Acesso em: 04 fev. 2021.

BANCO MUNDIAL. Pandémie de Covid-19: chocs pour l'éducation et reponses strategiques. [Washington]: BANCO MUNDIAL, 2020c. Disponível em: https://openknowledge.worldbank.org/bitstream/handle/10986/33696/148198FR.pdf?seq uence $=$ 5\&isAllowed=y. Acesso em: 04 fev. 2021.

BANCO MUNDIAL. Face aux conséquences de la COVID-19 sur l'éducation, il faut agir vite et efficacement. [Washington]: BANCO MUNDIAL, 2021a. Disponível em: https://www.banquemondiale.org/fr/news/immersive-story/2021/01/22/urgent-effectiveaction-required-to-quell-the-impact-of-covid-19-on-education-worldwide. Acesso em: 10 mar. 2021.

BANCO MUNDIAL. Agindo agora para proteger o capital humano de nossas crianças: os custos e a resposta ao impacto da pandemia de COVID-19 no setor de educação na América Latina e Caribe. [Washington]: BANCO MUNDIAL,2021b. Disponível em: https://reliefweb.int/sites/reliefweb.int/files/resources/Acting\%2onow-sumPT.pdf. Acesso em: 02 mar. 2021.

DALE, Roger. Globalização e educação: demonstrando a existência de uma "Cultura Educacional Mundial Comum" ou localizando uma "Agenda Globalmente Estruturada para a Educação"? Educação e Sociedade, Campinas, v. 25, n. 87, p. 423-460, maio/ago. 2004.

FRIGOTTO, Gaudêncio. A produtividade da escola improdutiva: um (re) exame das relações entre educação e estrutura social capitalista. São Paulo: Editora Cortez, 2006. 
FUNDO MONETÁRIO INTERNACIONAL - FMI. Mise a jour des perspectives de l'économie mondiale. [Washington]: FMI, jan./2021. Disponível em:

https://www.imf.org/fr/Publications/WEO/Issues/2021/01/26/2021-world-economic-outlookupdate. Acesso em: 01 mar. 2021.

LAVAL, Christian. La reforme mondiale de l'éducation. Revue de l'Association Française des Administrateurs de l'Éducation, [Les Lilas], n. 1, 2006. Disponível em:

http://institut.fsu.fr/La-reforme-mondiale-de-l-education. Acesso em: 01 fev. 2021.

LAVAL, Christian; WEBER, Louis (coord.). Le nouvel ordre éducatif mondial OMC, Banque mondiale, OCDE, Commission européenne. Paris: Syllepse, 2002. Disponível em:

https://www.researchgate.net/publication/44829166_Le_Nouvel_ordre_educatif_mondia I_OMC_Banque_mondiale_OCDE_Commission_europeenne/link $\overline{5} \overline{\mathrm{d}} \mathrm{d} 5 \mathrm{ffg} \overline{6} 2458515 \overline{\mathrm{d}} 6101 \mathrm{e} 23$ 87/download. Acesso em: 28 fev. 2021.

LEHER, Roberto. Um novo senhor da educação? A política educacional do Banco Mundial para a periferia do capitalismo. Outubro, São Paulo, v. 1, n. 3, p. 19-30, 1999.

LESSARD, Claude; MEIRIEU, Philippe. L'obligation de résultats em éducation. Quebec: De Boeck, 2005.

OCDE. Regards sur l'éducation 2020 : les Indicateurs de l'OCDE. Paris: OCDE, 2020 .

Disponível em: https://www.oecd.org/fr/education/regards-sur-

education/EAG2020_synthese_FR.pdf. Acesso em: 02 mar. 2021.

OCDE. El impacto del COVID-19 en la educación: información del panorama de la educación (education at a Glance). Paris: OCDE, 2020b. Disponível em:

https://www.oecd.org/centrodemexico/medios/EAG2020_COVID\%20Brochure\%20ES.pdfA cesso em: 04 mar. 2021.

OCDE. Positive, high-achieving students? what schools and teachers can do executive summary. Paris: OCDE, 2021. Disponível em: https://www.oecd-ilibrary.org/sites/3b9551dben/index.html?itemld=/content/publication/3b9551db-en. Acesso em: 04 mar. 2021.

OLIVEIRA, Dalila. Da promessa de futuro à suspensão do presente: a teoria do capital humano e o PISA na educação brasileira. Petrópolis: Editora Vozes, 2020.

ONU. Após um ano de COVID, a UNESCO convoca reunião global de ministros da educação para garantir a continuidade do aprendizado. Nova York: ONU, 2021. Disponível em: https://en.unesco.org/news/one-year-covid-unesco-convenes-global-meetingeducation-ministers-ensure-learning-continuity. Acesso em: 15 mar. 2021.

REIMERS, Fernando; SCHLEICHER, Andreas. Um Roteiro para guiar a resposta educacional à Pandemia da Covid-19. Paris: OECD, 2020a. Disponível em: http://s.oab.org.br/arquivos/2020/06/5c547620-3e7f-4ace-b7f4-51db3c2f2fad.pdf. Acesso em: 05 fev. 2021. 
REIMERS, Fernando; SCHLEICHER, Andreas. Educação interrompida. Educação repensada. Como a pandemia do Covid 19 está mudando a educação. Paris: OECD, 2020b. Disponível em:

https://ceipe.fgv.br/sites/ceipe.fgv.br/files/artigos/educacao_interrompida_o.pdf. Acesso em: 04 mar. 2021.

SAHLBERG, Pasi. How GERM is infecting schools around the world? 2012. Disponível em: https://pasisahlberg.com/text-test/. Acesso em: 15 jan. 2021.

SAHLBERG, Pasi. Education reform for raising economic competitiveness. Journal of Educational Change, New York, v. 7, n. 4, p. 259-287, 2006.

SCHULTZ, Theodore. 0 capital humano: investimentos em educação e pesquisa. Tradução de Marco Aurélio de Moura Matos. Rio de Janeiro: Zahar, 1973.

SHIROMA, Eneida. Redes, experts e a internacionalização de políticas educacionais.

Revista de Estudios Teóricos y Epistemológicos en Política Educativa, Buenos Aires, v. 5, p. 1-22, 2020.

UNESCO. Declaração Mundial sobre Educação para Todos. Jomtien: Conferência Mundial sobre Educação, 1990. Disponível em: https://www.unicef.org/brazil/declaracao-mundialsobre-educacao-para-todos-conferencia-de-jomtien-1990. Acesso em: 01 mar. 2021.

UNESCO. Educação um Tesouro a Descobrir. Relatório para a UNESCO da Comissão Internacional sobre Educação para o século XXI. São Paulo: Editora Cortez, 1998

UNESCO. Declaração de Dakar. Educação para Todos. Fórum Mundial da Educação, Dakar, 2000. Disponível em: http://www.direitoshumanos.usp.br/index.php/Direito-aEduca\%C3\%A7\%C3\%A30/declaracao-de-dakar.html. Acesso em: 02 mar. 2021.

UNESCO. Declaração de Incheon. Educação 2030. Fórum Mundial da Educação, Incheon, 2015. Disponível em: https://pt.unesco.org/fieldoffice/brasilia/expertise/education-2030brazil. Acesso em: 01 mar. 2021.

UNESCO. Action immédiate: atténuer l'incidence de la COVID-19 sur la réalisation de I'ODD 4. 2020a. Disponível em: file:///C:/Users/SAMSUNG/Downloads/374163fre\%20(2).pdf. Acesso em: 02 mar. 2021.

UNESCO. La COVID-19 représente une grave menace pour la relance de l'aide à l'éducation. 2020b. Disponível em: https://fr.unesco.org/gem-report/node/3141. Acesso em: 02 mar. 2021.

UNESCO. COVID-19: como a Coalizão Global de Educação da UNESCO está lidando com a maior interrupção da aprendizagem da história. 2020c. Disponível em: https://pt.unesco.org/news/covid-19-como-coalizao-global-educacao-da-unesco-estalidando-com-maior-interrupcao-da. Acesso em: 05 mar. 2021. 
UNESCO. Réunion mondiale sur l'éducation 2020. Session extraordinaire sur l'éducation post-COVID-19 (en ligne). Note conceptuelle. 2020d. Disponível em:

https://en.unesco.org/sites/default/files/gem2020-extraordinary-session-concept-notefr.pdf. Acesso em: 04 mar. 2021.

UNESCO. International Education Day 2021. Recover and Revitalize Education for the COVID-19 Generation. 2021. Disponível em:

https://en.unesco.org/sites/default/files/education-day-2021-concept-note-en.pdf. Acesso em: 10 mar. 2021.

VERGER, Antoni. Les Réformes Managériales Mondiales de l'Éducation. 2016. Disponível em: https://www.ei-ie.org/fr/woe_homepage/woe_detail/4542/las-reformas-educativasglobales-de-enfoque-gerencial-y--̄os-docentes. Acesso em: 10 jan. 2021.

VERGER, Antoni. A política educacional global: conceitos e marcos teóricos chave. Práxis Educativa, Ponta Grossa, v. 14, n. 1, p. 9-33, jan./abr. 2019. 